\title{
Growth and Performance of Cashew Nut Production in India- An Analysis
}

\author{
E. Elakkiya ${ }^{1^{*}}$, P. Sivaraj ${ }^{2}$ and A. Vijayaprabhakar ${ }^{3}$ \\ ${ }^{1}$ Department of Physical Sciences and Information Technology, ${ }^{2}$ Department of Agricultural \\ Extension and Rural Sociology, ${ }^{3}$ Department of Agronomy, Tamil Nadu Agricultural University, \\ Coimbatore- 641003, Tamil Nadu, India \\ *Corresponding author
}

\section{A B S T R A C T}

\begin{tabular}{|c|}
\hline Keywords \\
\hline $\begin{array}{l}\text { Cashew nut, } \\
\text { Growth, } \\
\text { Performance, } \\
\text { Statistics and Trend }\end{array}$ \\
\hline Article Info \\
\hline $\begin{array}{l}\text { Accepted: } \\
23 \text { May } 2017 \\
\text { Available Online: } \\
10 \text { June } 2017\end{array}$ \\
\hline
\end{tabular}

\section{Introduction}

The cashew nut has been introduced into India in $16^{\text {th }}$ century in order to prevent soil erosion only. Later the kernels from cashew nut become a major source of income for most of the people in coastal tropical regions of India. India has always been a major player in the production of cashew.

It is the largest producer, processor, consumer and exporter of cashew in the world. India led the production of cashews in 2015-16 with a crop of 172,719 metric tons (kernel basis), which represented the 23.00 percent of global production. In India cashew is being grown in an area of 10.27 lakh hectares with a total production of 7.25 lakh MT of raw nuts and unit area productivity of $706 \mathrm{~kg} / \mathrm{ha}$. According to the estimates by the Directorate of Cashew nut \& Cocoa Development, the production of raw cashew nuts in India during 2015-2016 was 6,82,000 M T and area of 1035 hectare as against the estimate production of 7,44,000 M T during 20142015.

The main objective of the paper is highlight the growth and performance of the cashew nut production in India and compared with the large and small sample data during 1965-66 to 2015-16 (large size) and 1990-91 to 2015-16 (small size). The secondary data were collected from the Directorate of Cashew and Cocoa Development (www.indiastat.com).

\section{Materials and Methods}

The leading cashew nut production state was selected for the study, based on 1965-66 to 
2015-16 yearly data. The purposively to select first six leading states in cashew nut production namely Maharashtra, Kerala, Andhra Pradesh, Orissa, Karnataka and Tamil Nadu for the study.

\section{Descriptive Statistics}

The branch of statistics is devoted to the summarization and description of data (population or sample) is called descriptive statistics. Descriptive statistics are used to present quantitative descriptions in a manageable form. In an agricultural research, we have lots of measures. It is help us to simply large amount of data in a sensible way. Each descriptive statistics reduces lots of data into a simple summary.

To study the nature of each sequence these have been exposed to get various statistics. Descriptive statistics are used to define the elementary structures of the data in a study. They provide simple summaries about the sample and the measures. Together with simple graphics analysis, they form the basis of virtually every quantitative analysis of data. Descriptive statistics are typically distinguished from inferential statistics. With descriptive statistics we are simply describing what is or what the data shows. Statistical tools used to define the above series are minimum, maximum, average, standard error, skewness and kurtosis.

\section{Percentage analysis}

Percentage Analysis is applied to create a contingency table from the frequency distribution and represent the collected data for better understanding. Percentage analysis is the method to represent raw streams of data as a percentage (a part in 100 - percent) for better understanding of collected data. If specify one variable as causing or influencing a second variable, the first variable is called the independent variable and the latter is called the dependent variable. It should percentage in the direction of independent variable.

\section{Results and Discussion}

\section{Descriptive statistics for large samples}

Descriptive statistics stated in table 1. The descriptive statistics demonstrates the mean, median, standard deviation, maximum and minimum values along with other statistical properties. The production of cashew product shows volatile pattern. There was standard deviation value of non-zero. The coefficient of variation was used statistic for comparing the degree of variation from one data series to another, even if the means are severely different from each other. It was calculate as the ratio of standard deviation to mean. The coefficient of variation was $57.70 \%$. B2 (kurtosis) value (-1.244) of production indicates there platykurtic in nature. Positive values of skewness expose that starting from the initial years of the period under study a continuous effort was there to increase the yield of cashew nut. Table 1 shows that the descriptive statistics for 51 years cashew nut production in India (i.e. large samples).

\section{Descriptive statistics for small samples}

The descriptive statistics demonstrates the mean, median, standard deviation, maximum and minimum values along with other statistical properties. The production of cashew product shows volatile pattern. There was standard deviation value of non-zero. The coefficient of variation is a useful statistic for comparing the degree of variation from one data series to another, even if the means are severely different from each other. It was calculate the ratio of standard deviation to mean. The coefficient of variation is $26.84 \%$. B2 (kurtosis) value (-1.107) of production 
indicates there platykurtic in nature. Positive values of skewness expose that starting from the initial years of the period under study a continuous effort was there to increase the yield of cashew nut. Table 2 shows that the descriptive statistics for 51 years cashew nut production in India (i.e. small samples).

Table.1 Descriptive statistics for cashew nut production in India for large samples (1965 to 2016)

\begin{tabular}{|c|l|r|}
\hline S. No. & \multicolumn{2}{|c|}{ Descriptive statistics } \\
\hline 1. & Mean & 367.5607843 \\
\hline 2. & Standard Error & 29.70248238 \\
\hline 3. & Median & 321.6 \\
\hline 4. & Standard Deviation & 212.1181521 \\
\hline 5. & Sample Variance & 44994.11043 \\
\hline 6. & Coefficient of variation (\%) & 57.70 \\
\hline 7. & Kurtosis & -1.244007266 \\
\hline 8. & Skewness & 0.424808435 \\
\hline 9. & Range & 649.4 \\
\hline 10. & Minimum & 103.8 \\
\hline 11. & Maximum & 753.2 \\
\hline 12. & Sum & 18745.6 \\
\hline 13. & Count & 51 \\
\hline 14. & Confidence Level (95.0\%) & 59.65919163 \\
\hline
\end{tabular}

Table.2 Descriptive statistics for cashew nut production in India for small samples (1990 to 2016)

\begin{tabular}{|c|l|r|}
\hline S.No. & \multicolumn{2}{|c|}{ Descriptive statistics } \\
\hline 1. & Mean & 533.448 \\
\hline 2. & Standard Error & 28.63411958 \\
\hline 3. & Median & 533.6 \\
\hline 4. & Standard Deviation & 143.1705979 \\
\hline 5. & Sample Variance & 20497.8201 \\
\hline 6. & Coefficient of variation (\%) & 26.84 \\
\hline 7. & Kurtosis & -1.106674347 \\
\hline 8. & Skewness & 0.032418559 \\
\hline 9. & Range & 458.6 \\
\hline 10. & Minimum & 294.6 \\
\hline 11. & Maximum & 753.2 \\
\hline 12. & Sum & 13336.2 \\
\hline 13. & Count & 25 \\
\hline 14. & Confidence Level $(95.0 \%)$ & 59.09791821 \\
\hline
\end{tabular}


Table.3 Cashew nut production in the major producing states in India during 1995 to 2015 (In Million Tonnes)

\begin{tabular}{|c|c|c|c|c|c|c|c|}
\hline Year & Maharastra & Kerala & $\begin{array}{l}\text { Andhra } \\
\text { Pradesh }\end{array}$ & Orissa & Karnataka & $\begin{array}{l}\text { Tamil } \\
\text { Nadu }\end{array}$ & $\begin{array}{c}\text { Total } \\
\text { production }\end{array}$ \\
\hline $1965-66$ & 2.7 & 73.0 & 7.0 & 1.5 & 6.0 & 10.3 & 103.8 \\
\hline $1966-67$ & 2.1 & 81.6 & 7.2 & 1.4 & 4.6 & 110 & 213.2 \\
\hline $1967-68$ & 2.3 & 82.6 & 7.9 & 1.4 & 6.8 & 10.8 & 118.5 \\
\hline 1968-69 & 2.4 & 82.7 & 8.5 & 1.4 & 7.0 & 11.8 & 120.4 \\
\hline 1969-70 & 3.5 & 83.0 & 9.0 & 1.2 & 7.5 & 12.6 & 123.3 \\
\hline 1970-71 & 3.5 & 85.4 & 9.0 & 1.3 & 8.5 & 12.5 & 127.2 \\
\hline 1971-72 & 3.8 & 85.9 & 9.2 & 1.3 & 9.7 & 12.3 & 131.0 \\
\hline $1972-73$ & 3.7 & 86.8 & 10.1 & 1.5 & 10.5 & 9.6 & 129.8 \\
\hline 1973-74 & 3.6 & 89.8 & 12.0 & 2.0 & 11.3 & 9.0 & 135.5 \\
\hline $1974-75$ & 4.2 & 95.9 & 12.8 & 2.5 & 12.3 & 8.7 & 144.3 \\
\hline 1975-76 & 4.2 & 107.2 & 12.6 & 3.9 & 15.2 & 10.5 & 161.5 \\
\hline 1976-77 & 4.3 & 107.5 & 12.5 & 3.9 & 15.2 & 10.2 & 162.5 \\
\hline $1977-78$ & 4.8 & 108.2 & 13.4 & 4.0 & 15.7 & 10.2 & 165.3 \\
\hline $1978-79$ & 7.2 & 110.5 & 14.0 & 4.3 & 16.0 & 10.0 & 171.8 \\
\hline $1979-80$ & 6.0 & 116.0 & 16.0 & 5.0 & 16.0 & 11.0 & 180.3 \\
\hline $1980-81$ & 8.0 & 117.0 & 16.5 & 6.0 & 16.5 & 11.0 & 185.3 \\
\hline 1981-82 & 10.0 & 118.0 & 20.0 & 8.0 & 18 & 10.5 & 195.8 \\
\hline $1982-83$ & 10.0 & 120.9 & 20.0 & 8.5 & 19.1 & 11.3 & 201.4 \\
\hline 1983-84 & 12.4 & 123.7 & 2.2 & 10.0 & 19.1 & 11.3 & 190.9 \\
\hline $1984-85$ & 14.1 & 126.6 & 24.4 & 11.9 & 20.0 & 11.6 & 221.3 \\
\hline 1985-86 & 15.8 & 128.9 & 26.8 & 16.9 & 20.9 & 11.8 & 234.5 \\
\hline $1986-87$ & 19.1 & 130.9 & 29.1 & 18.6 & 22.0 & 11.9 & 245.6 \\
\hline $1987-88$ & 21.4 & 134.0 & 31.9 & 22.3 & 22.9 & 12.0 & 260.3 \\
\hline $1988-89$ & 24.4 & 136.9 & 34.3 & 26.8 & 23.7 & 12.4 & 274.3 \\
\hline $\begin{array}{l}1989-90 \\
\end{array}$ & 271.1 & 139.0 & 36.6 & 28.6 & 24.7 & 12.4 & 529.6 \\
\hline 1990-91 & 29.52 & 142.1 & 37.8 & 29.1 & 25.8 & 12.47 & 294.6 \\
\hline 1991-92 & 31.96 & 155.5 & 71.2 & 60.1 & 74.4 & 12.71 & 533.6 \\
\hline 1992-93 & 43.75 & 151.6 & 44.9 & 39.1 & 31.3 & 19.19 & 349.2 \\
\hline 1993-94 & 46.86 & 140.2 & 46.6 & 43.4 & 31.5 & 19.2 & 348.4 \\
\hline 1994-95 & 37.6 & 119.2 & 58.7 & 37.2 & 26.4 & 22.0 & 321.6 \\
\hline $\begin{array}{l}1995-96 \\
\end{array}$ & 69.0 & 140.0 & 71.7 & 43.0 & 37.6 & 30.9 & 417.8 \\
\hline 1996-97 & 80.0 & 134.0 & 60.0 & 40.0 & 52.0 & 30.0 & 430.0 \\
\hline $1997-98$ & 60.0 & 100.0 & 50.0 & 45.0 & 35.0 & 30.0 & 360.0 \\
\hline $\begin{array}{l}1998-99 \\
\end{array}$ & 85.0 & 130.0 & 80.0 & 50.0 & 40.0 & 35.0 & 460.0 \\
\hline 1999-00 & 125.0 & 100.0 & 100.0 & 40.0 & 60.0 & 45.0 & 520.0 \\
\hline $2000-01$ & 98.0 & 76.0 & 75.0 & 59.0 & 42.0 & 59.0 & 450.0 \\
\hline 2001-02 & 103.0 & 87.0 & 88.0 & 59.0 & 40.0 & 46.0 & 472.0 \\
\hline $2002-03$ & 115.0 & 94.0 & 98.0 & 55.0 & 44.0 & 50.0 & 506.0 \\
\hline 2003-04 & 120.0 & 95.0 & 95.0 & 71.0 & 46.0 & 51.0 & 535.0 \\
\hline 2004-05 & 174.0 & 64.0 & 88.0 & 74.0 & 43.0 & 53.0 & 544.0 \\
\hline
\end{tabular}




\begin{tabular}{|c|r|r|r|r|r|r|r|}
\hline $2005-06$ & 183.0 & 67.0 & 92.0 & 78.0 & 45.0 & 56.0 & 573.0 \\
\hline $2006-07$ & 197.0 & 72.0 & 99.0 & 84.0 & 52.0 & 60.0 & 620.0 \\
\hline $2007-08$ & 210.0 & 78.0 & 107.0 & 90.0 & 56.0 & 65.0 & 665.0 \\
\hline $2008-09$ & 225.0 & 75.0 & 112.0 & 95.0 & 60.0 & 68.0 & 695.0 \\
\hline $2009-10$ & 198.0 & 76.0 & 99.0 & 84.0 & 53.0 & 60.0 & 613.0 \\
\hline $2010-11$ & 208.0 & 71.0 & 107.0 & 91.0 & 57.0 & 65.0 & 653.0 \\
\hline $2011-12$ & 216.0 & 74.0 & 113.6 & 96.0 & 66.0 & 60.0 & 725.2 \\
\hline $2012-13$ & 77.0 & 0 & 0 & 224.6 & 0 & 12.1 & 751.7 \\
\hline $2013-14$ & 236.2 & 80.1 & 100.4 & 85.7 & 80.6 & 67.4 & 753.2 \\
\hline $2014-15$ & 235.0 & 80.0 & 100.0 & 85.5 & 80.5 & 67.0 & 744.9 \\
\hline Total & 3668.49 & 5073.7 & 2397.9 & 1952.9 & 1548.3 & 1471.67 & 18063.6 \\
\hline Percent & $\mathbf{2 0 . 3 0 8 7 4 2}$ & $\mathbf{2 8 . 0 8 8}$ & $\mathbf{1 3 . 2 7 4 7 6 2 5}$ & $\mathbf{1 0 . 8 1 1 2 4 5}$ & $\mathbf{8 . 5 7 1 3 8 1 1}$ & $\mathbf{8 . 1 4 7 1 5 7 8}$ & \\
\hline Rank & II & I & III & IV & V & VI & \\
\hline
\end{tabular}

Table.4 Cashew nut production in the major producing states in India during 1990 to 2015 (In Million Tonnes)

\begin{tabular}{|c|c|c|c|c|c|c|c|}
\hline Year & Maharashtra & Kerala & Andhra Pradesh & Orissa & Karnataka & $\begin{array}{l}\text { Tamil } \\
\text { Nadu }\end{array}$ & \begin{tabular}{|l|} 
Total \\
production
\end{tabular} \\
\hline 1990-91 & 29.52 & 142.1 & 37.8 & 29.1 & 25.8 & 12.47 & 294.6 \\
\hline $1991-92$ & 31.96 & 155.5 & 71.2 & 60.1 & 74.4 & 12.71 & 533.6 \\
\hline $1992-93$ & 43.75 & 151.6 & 44.9 & 39.1 & 31.3 & 19.19 & 349.2 \\
\hline 1993-94 & 46.86 & 140.2 & 46.6 & 43.4 & 31.5 & 19.2 & 348.4 \\
\hline 1994-95 & 37.6 & 119.2 & 58.7 & 37.2 & 26.4 & 22.0 & 321.6 \\
\hline $1995-96$ & 69.0 & 140.0 & 71.7 & 43.0 & 37.6 & 30.9 & 417.8 \\
\hline 1996-97 & 80.0 & 134.0 & 60.0 & 40.0 & 52.0 & 30.0 & 430.0 \\
\hline $1997-98$ & 60.0 & 100.0 & 50.0 & 45.0 & 35.0 & 30.0 & 360.0 \\
\hline $1998-99$ & 85.0 & 130.0 & 80.0 & 50.0 & 40.0 & 35.0 & 460.0 \\
\hline 1999-00 & 125.0 & 100.0 & 100 & 40.0 & 60.0 & 45.0 & 520.0 \\
\hline $2000-01$ & 98.0 & 76.0 & 75.0 & 59.0 & 42.0 & 59.0 & 450.0 \\
\hline $2001-02$ & 103.0 & 87.0 & 88.0 & 59.0 & 40.0 & 46.0 & 472.0 \\
\hline $2002-03$ & 115.0 & 94.0 & 98.0 & 55.0 & 44.0 & 50.0 & 506.0 \\
\hline 2003-04 & 120.0 & 95.0 & 95.0 & 71.0 & 46.0 & 51.0 & 535.0 \\
\hline 2004-05 & 174.0 & 64.0 & 88.0 & 74.0 & 43.0 & 53.0 & 544.0 \\
\hline $2005-06$ & 183.0 & 67.0 & 92.0 & 78.0 & 45.0 & 56.0 & 573.0 \\
\hline $2006-07$ & 197.0 & 72.0 & 99.0 & 84.0 & 52.0 & 60.0 & 620.0 \\
\hline $2007-08$ & 210.0 & 78.0 & 107 & 90.0 & 56.0 & 65.0 & 665.0 \\
\hline 2008-09 & 225.0 & 75.0 & 112 & 95.0 & 60.0 & 68.0 & 695.0 \\
\hline $2009-10$ & 198.0 & 76.0 & 99.0 & 84.0 & 53.0 & 60.0 & 613.0 \\
\hline $2010-11$ & 208.0 & 71.0 & 107 & 91.0 & 57.0 & 65.0 & 653.0 \\
\hline 2011-12 & 216.0 & 74.0 & 113.6 & 96.0 & 66.0 & 60.0 & 725.2 \\
\hline 2012-13 & 77.0 & 0 & 0 & 224.6 & 0 & 12.1 & 751.7 \\
\hline 2013-14 & 236.2 & 80.1 & 100.4 & 85.7 & 80.6 & 67.4 & 753.2 \\
\hline 2014-15 & 235 & 80.0 & 100.0 & 85.5 & 80.5 & 67.0 & 744.9 \\
\hline Total & 3203.89 & 2401.7 & 1994.9 & 1758.7 & 1179.1 & 1095.97 & 13336.2 \\
\hline Percent & 24.02401 & 18.0089 & 14.95853392 & 13.1874 & 8.8413491 & 8.2180081 & \\
\hline Rank & $\mathrm{I}$ & II & III & IV & $\mathrm{V}$ & VI & \\
\hline
\end{tabular}




\section{Comparing with large and small samples with descriptive statistics}

When compared with the large samples and small samples, it would be moderate different from the standard error, confidence level, kurtosis and skewness. Whether highly different from mean, standard deviation, sample variance and coefficient of variance. In the coefficient of variance (CV) was unitfree measure. The $\mathrm{CV}$ value would be small if the variation was small. In small sample has the less variation. From this study the consistency of two samples, the small sample with less coefficient of variation $(\mathrm{CV})$, it represents to be small sample is more consistent when compared with large sample.

\section{Percentage analysis}

The large samples (i.e. 1965-66 to 2014-15 years) were showed in table 3 and Kerala state was the leading cashew nut producer state in India. They produce 28.09 per cent of total production from India. Maharashtra was the second largest producer state of cashew nut in India. They produce 20.31 per cent of total production followed by Andhra Pradesh, Orissa, Karnataka and Tamil Nadu are occupied third, fourth, fifth and sixth largest producer state of cashew nut in India. They produce $13.27 \%, 10.81 \%, 8.57 \%$ and 8.15 per cent, respectively of total production. Poor qualities of cashews are grown in some states, which is due to the natural calamities, drought, pest and diseases.

The small samples (i.e. 1990-91 to 2014-15 years) as showed in table 4, Maharashtra was the leading state of cashew nut producer in India. They produce 24.02 per cent of total production from India. Kerala was the second largest producer state of cashew nut in India. They produce 18.01 per cent of total production followed by Andhra Pradesh, Orissa, Karnataka and Tamil Nadu are occupied third, fourth, fifth and sixth largest producer state of cashew nut in India. They produce $14.96 \%, 13.19 \%, 8.84 \%$ and 8.15 per cent, respectively of total production. Poor qualities of cashews are grown in some states, which is due to the wrong harvesting techniques.

The results conclude that the cashew nut production in India was increased during selected period from 1965-66 to 2014-15. In small sample have less variation and more consistent (i.e. less CV value) when compared with large sample. In large samples, Kerala state has the largest cashew nut production during 1965-66 onwards. But the small samples, Maharashtra state has been largest cashew nut production around 1990-91 years. In that year, Kerala has been poor qualities of cashews. So only the cashew production would be decreased. But other states (i.e. Andhra Pradesh, Orissa, Karnataka and Tamil $\mathrm{Nadu}$ ) are does not change the position of the cashew nut production for large and small samples.

Moreover, from these results lightning call for policy makers and development departments to implement suitable programmes to reverse the scenario so as to build confidence and to improve status of cashew growers by making farming as a profitable occupation. Departments need to make supporting price, insurance to cashew and subsidies has to be given to cashew growers in order to sustain their livelihood security. These supportive measures taken by the government through respected and line department people will help the farmers to get maximum profit from cashew nut cultivation.

\section{References}

Mishra, P., Debnath, M. K., Vishwajith K. P., Basavanneppa, B. B., and Sahu, P. K. 2014. Modeling and instability analysis 
of rice in India and their yield sustainability. Indian Journal of Sciences Research and Technology. 2(5): 73- 81.

Mishra, P., P. K. Sahu, B. S. Dhekale and Vishwajith K. P. 2015.Modeling and Forecasting of Wheat in India and Their
Yield Sustainability Indian $J$ Econ Dev.11 (3): 637-647.

Purna Chandra Padhan. 2012. Application of ARIMA Model for Forecasting Agricultural Productivity in India. Journal of Agriculture \& Social Sciences, Vol. 8, No. 2.

\section{How to cite this article:}

Elakkiya, E., P. Sivaraj and Vijaya Prabhakar, A. 2017. Growth and Performance of Cashew Nut Production in India- An Analysis. Int.J.Curr.Microbiol.App.Sci. 6(6): 1817-1823. doi: https://doi.org/10.20546/ijcmas.2017.606.211 